Jurnal Dinamis

Vol. 9, No. 2, Bulan Tahun | 12-21

ISSN : 0216-7492, e-ISSN : 2809-3410

Homepage: https://talenta.usu.ac.id/dinamis

\title{
ANALISA SIFAT MEKANIK DAN STRUKTUR MIKRO TERHADAP PENGELASAN BAJA AISI 1045 DENGAN METODE SMAW DAN GTAW PADA ARUS 100 AMPERE
}

\author{
Reymond Reflon F Gultom ${ }^{1 *}$, Muhammad Sabri ${ }^{2}$ \\ Departemen Teknik Mesin, Fakultas Teknik, Universitas Sumatera Utara \\ *Email: reflonreymond@gmail.com
}

\begin{abstract}
ABSTRAK
Pengelasan adalah proses penyambungan logam atau non-logam yang dilakukan dengan memanaskan material yang akan disambung hingga temperatur las, yang dilakukan dengan atau tanpa menggunakan tekanan dan dengan atau tanpa menggunakan logam pengisi. Salah satu teknik pengelasan adalah dengan pengelasan SMAW (Shield Metal Arc Welding) dan GTAW (Gas Tungsen Arc Welding). Dengan las tersebut kita dapat menyambung logam seperti: Aluminium, Tembaga, Carbon Steel, dan Stainless Steel. Penelitian ini dilakukan untuk mengetahui sifat mekanik, struktur mikro, dan kekuatan sambungan las pada Baja AISI 1050. Pengelasan dilakukan dengan menggunakan tungsten TG-S50 untuk las GTAW dan elektroda E-6013 untuk las SMAW pada arus 100 Ampere dengan sambungan kampuh V 60. Metode pengujian yang dilakukan adalah uji kekerasan dengan metode Brinell Hardness Tester, uji tarik dengan Tensile Tester, dan uji struktur mikro dengan Metallurgycal Microscope. Hasil rata-rata dari uji kekerasan Brinell didapat sifat mekanik baja AISI 1045 las SMAW pada daerah las dengan elektroda E-6013 pada arus 100 A adalah 160,04 BHN dan las GTAW dengan filer TGS50 pada arus 100 A adalah 172,53 BHN. Nilai rata-rata tegangan las SMAW dengan elektroda E-6013 pada arus 100 A adalah 323,14 MPa dan las GTAW dengan filler TG-S50 pada arus 100 A adalah 411,57 MPa. Bentuk struktur mikro pada daerah lasan dengan pengelasan GTAW memiliki struktur mikro yang lebih kecil dibandingkan dengan pengelasan SMAW, hal ini membuktikan bahwa nilai kekerasan pada daerah lasan GTAW lebih besar dari pada nilai kekerasan pada daerah lasan SMAW.
\end{abstract}

Kata kunci : Las SMAW, Las GTAW, Baja AISI 1045, Sambungan las

\begin{abstract}
Welding is a metal or non-metal joining process carried out by heating the material to be joined to the welding temperature, which is carried out with or without the use of pressure and with or without the use of filler metal. One of the welding techniques is SMAW (Shield Metal Arc Welding) and GTAW (Gas Tungsen Arc Welding) welding. With this welding we can connect metals such as: Aluminum, Copper, Carbon Steel, and Stainless Steel. This research was conducted to determine the mechanical properties, microstructure, and strength of the welded joint on AISI 1050 Steel. Welding was carried out using tungsten TG-S50 for GTAW welding and E-6013 electrode for SMAW welding at a current of 100 Ampere with a seam V 60o connection. The testing method used is the hardness test using the Brinell Hardness Tester method, the tensile test using the Tensile Tester, and the microstructure test using the Metallurgycal Microscope. The average results of the Brinell hardness test obtained that the mechanical properties of AISI 1045 SMAW steel in the welding area with the E-6013 electrode at a current of $100 \mathrm{~A}$ were $160.04 \mathrm{BHN}$ and the GTAW welding with a TG-S50 filer at a current of $100 \mathrm{~A}$ was 172.53 BHN. . The average value of the SMAW welding voltage with the E-6013 electrode at a current of $100 \mathrm{~A}$ is 323.14 $\mathrm{MPa}$ and the GTAW welding with TG-S50 filler at a current of $100 \mathrm{~A}$ is $411.57 \mathrm{MPa}$. The shape of the microstructure in the GTAW welding area has a smaller microstructure than SMAW welding, this proves that the hardness value in the GTAW weld area is greater than the hardness value in the SMAW weld area.
\end{abstract}

Keywords: SMAW Welding,GTAW Welding, AISI 1045 Steel, Welding Joint 


\section{PENDAHULUAN}

Saat ini teknik penyambungan logam di bidang pengelasan sudah berkembang pesat. Pada konstruksi yang menggunakan bahan baku logam, hampir sebagian besar sambungannya dikerjakan dengan cara pengelasan. Pengelasan juga banyak digunakan untuk pengerjaan konstruksi gedung, jembatan, perpipaan dan otomotif. Selain untuk penyambungan, proses las juga dapat digunakan untuk reparasi, misalnya untuk mengisi lubang - lubang pada coran, membuat lapisan pada perkakas, mempertebal bagian yang sudah aus dan reparasi lainnya. Seperti yang kita ketahui, ada banyak jenis pengelasan yang digunakan pada saat ini. Beberapa jenisnya ialah Gas Tungsten Arc Welding (GTAW) dan Shield Metal Arc Welding (SMAW).Yang sering menjadi permasalahan ialah ketika kekuatan dari hasil lasan tidak sesuai dengan yang ditargetkan. Hal tersebut sering terjadi diakibatkan oleh terbentuknya cacat las pada saat proses pengelasan berlangsung dan cacat las yang terbentuk sering ada pada hasil las dengan metode GTAW maupun SMAW.

Perbedaan dari las GTAW dan SMAW paling terlihat pada elektroda dan jenis pelindungnya ,elektroda pada las GTAW yaitu tungsten tidak akan habis jika di gunakan karena logam pengisi pada las GTAW adalah filler sedangkan pada las SMAW elektroda terbakar habis menjadi logam pengisi dan pada bagian pelindung las GTAW menggunakan pelindung gas mulia yaitu Argon (Ar) dan SMAW menggunakan flux yang terdapat pada elektroda.

\section{TEORI DASAR Definisi Pengelasan}

Menurut American Welding Society (AWS) pengelasan adalah proses penyambungan logam atau nonlogam yang dilakukan dengan memanaskan material yang akan disambung hingga temperatur las, yang dilakukan dengan atau tanpa menggunakan tekanan dan dengan atau tanpa menggunakan logam pengisi. Definisi tersebut dapat diartikan lebih lanjut bahwa pengelasan adalah suatu aktifitas menyambung dua bagian benda atau lebih dengan atau tanpa bahan tambah (filler metal) yang sama ataupun berbeda titik maupun strukturnya.

Sedangkan definisi pengelasan menurut British Standard Institution (1983), pengelasan adalah proses penyambungan antara dua atau lebih material dalam keadaan plastis atau cair dengan menggunakan panas (heat) atau dengan tekanan (pressure) atau keduanya. Logam pengisi (filler metal) dengan temperatur lebur yang sama dengan titik lebur dari logam induk dapat atau tanpa digunakan dalam proses penyambungan tersebut.

\section{Gas Tungsten Arc Welding (GTAW) dan Shield Metal Arc Welding (SMAW)}

Gas Tungsten Arc Welding (GTAW) adalah suatu proses pengelasan dengan menggunakan busur nyala yang dihasilkan oleh elektroda tetap yang terbuat dari tungsten. GTAW adalah suatu proses pengelasan busur listrik elektroda tidak terumpan, dengan menggunakan gas mulia sebagai pelindung terhadap pengaruh udara luar. Pada proses pengelasan GTAW peleburan logam terjadi karena panas yang dihasilkan oleh busur listrik antara elektroda dengan logam induk. Elektroda ini digunakan hanya untuk menghasilkan busur nyala listrik, sedangkan bahan penambah terbuat dari bahan yang sama atau sejenis dengan bahan yang akan dilas dan terpisah dari pistol las. Bahan penambah pada las GTAW, berupa batang las (rod) yang dicairkan oleh busur nyala tersebut dan mengisi kampuh bahan induk. Gas pelindung yang digunakan dalam pengelasan biasanya berupa gas Argon 99\%.

Las SMAW yang berasal dari kata Shield Metal Arc Welding adalah proses pengelasan yang menggunakan panas untuk mencairkan material dasar atau logam induk dan elektroda (kawat las). Panas tersebut ditimbulkan oleh lompatan ion listrik yang terjadi antara katoda dan anoda (ujung elektroda dan permukaan plat yang akan dilas). Panas yang timbul dari lompatan ion listrik ini besarnya dapat mencapai $4000^{\circ}$ sampai $4500^{\circ} \mathrm{C}$. Las listrik ini menggunakan elektroda berselaput sebagai bahan tambah. Busur listrik yang terjadi diantara ujung elektroda dan bahan dasar akan mencairkan ujung elektroda dan sebagian bahan dasar. Selaput elektroda yang turut terbakar akan mencair dan menghasilkan gas yang melindungi ujung elektroda, kawah Ias, busur listrik dan daerah Ias di sekitar busur listrik terhadap pengaruh udara luar. Cairan selaput elektroda yang membeku akan menutupi permukaan Ias yang juga berfungsi sebagai pelindung terhadap pengaruh luar. Logam induk dalam pengelasan ini mengalami pencairan akibat pemanasan dari busur listrik yang timbul antara ujung elektroda dan permukaan benda kerja. Busur listrik dibangkitkan dari suatu mesin las. Elektroda yang digunakan berupa kawat yang dibungkus pelindung berupa fluks. Elektroda ini selama pengelasan akan mengalami pencairan bersama dengan logam induk dan membeku bersama menjadi bagian kampuh las. 
Jurnal Dinamis USU, Vol. 9, No. 2 (Bulan, Tahun) |12-21

\section{METODOLOGI PENELITIAN}

1. Studi literatur

2. Diskusi interaktif

3. Proses pengelasan

4. Pembentukan spesimen uji tarik

5. Pengujian Tarik

6. Uji kekerasan

7. Uji Struktur Mikro

8. Analisa Data 


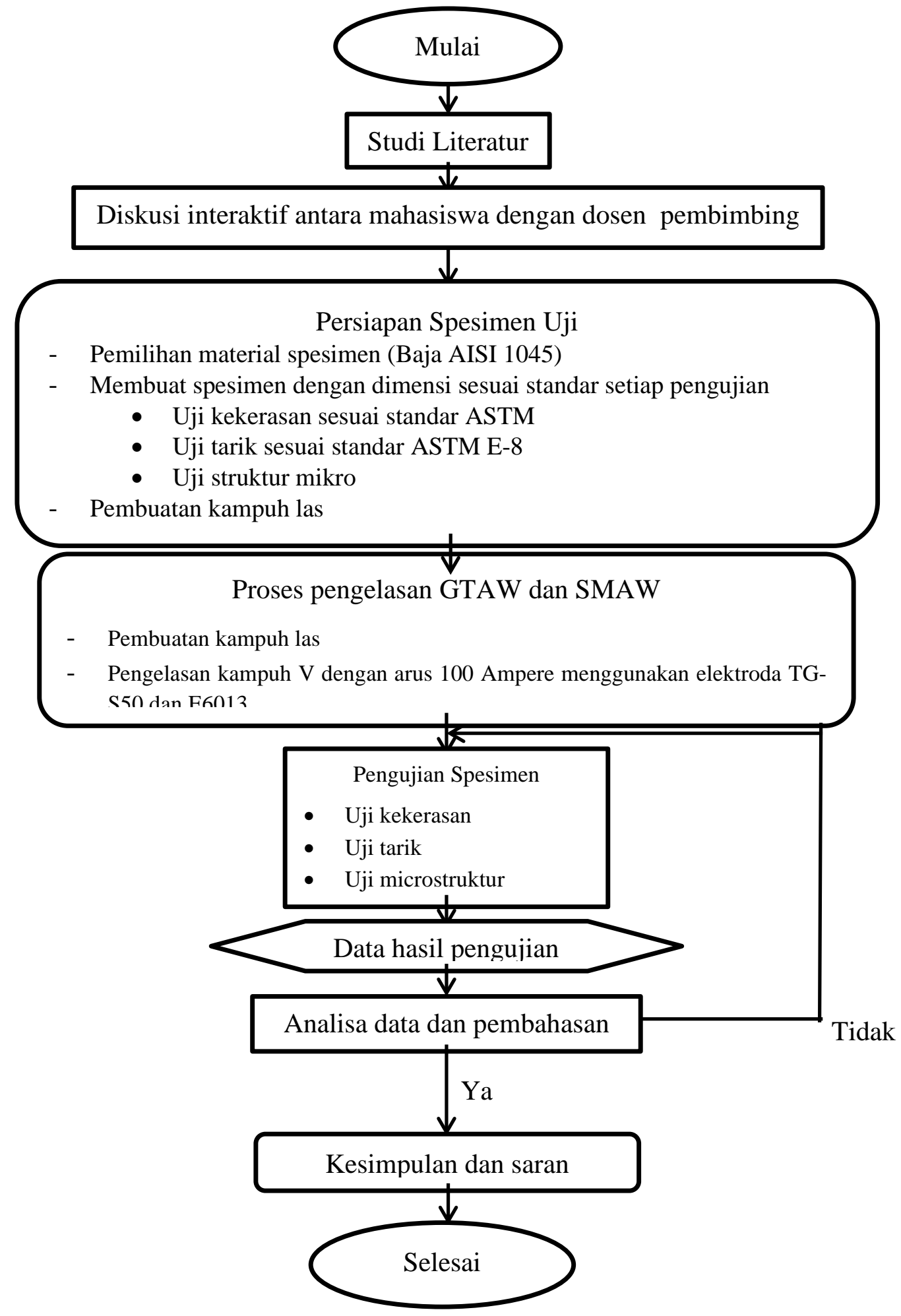

Gambar 1 Diagram alir penelitian 
HASIL

HASIL UJI KEKERASAN (HARDNESS TEST)

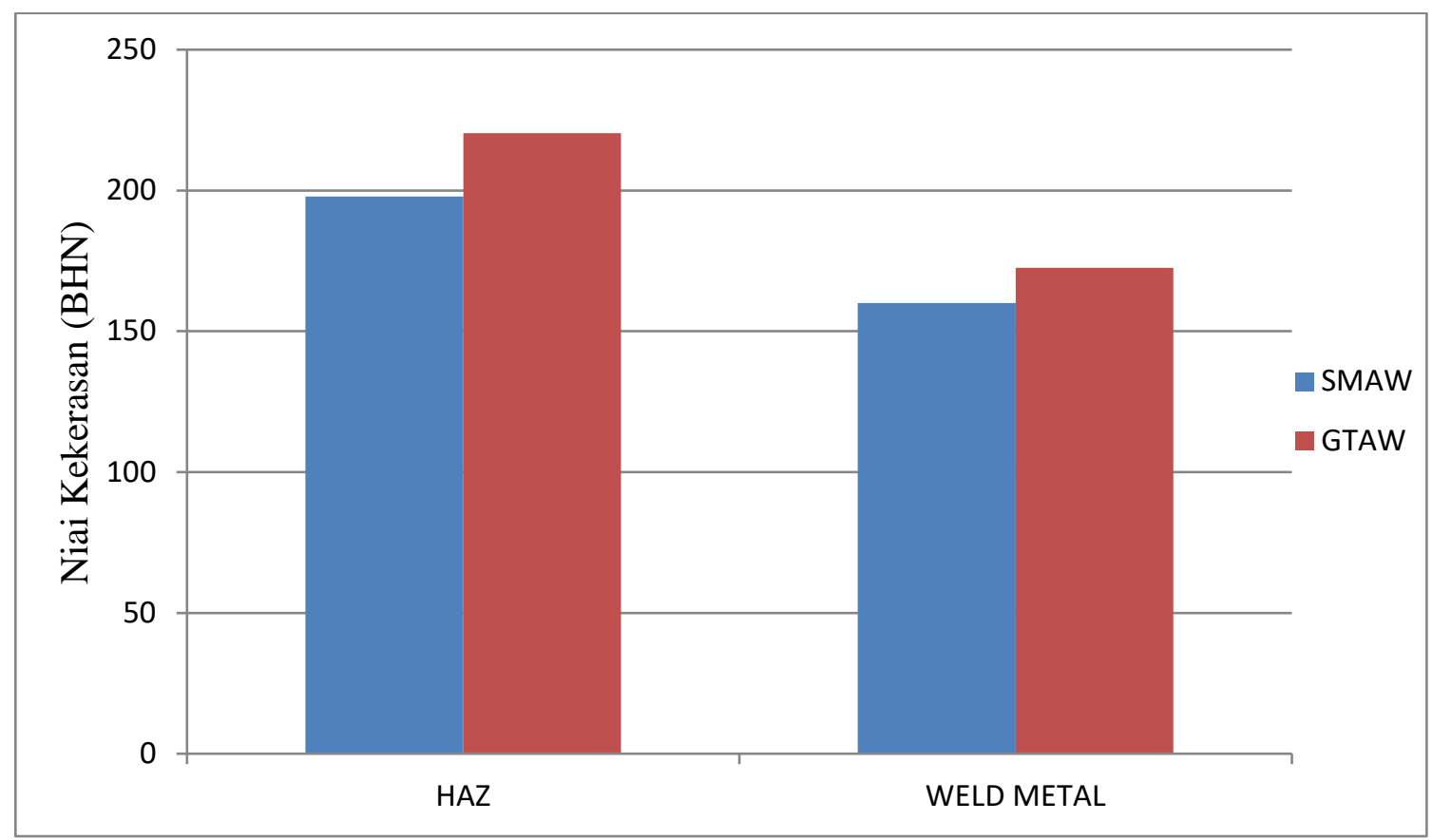

Nilai kekerasan Brinell terbesar pada titik uji HAZ terdapat 34ad alas GTAW dengan rata-rata nilai 220,29 BHN, dan pada titik uji las (Weld Metal) terdapat pada las GTAW dengan rata-rata nilai 172,53 BHN. Sedangkan nilai kekerasan terkecil pada titik uji HAZ terdapat pada las SMAW dengan rata-rata nilai 197,89 BHN, dan pada titik las (Weld Metal) terdapat pada las SMAW dengan nilai 160,04 BHN.

\section{Hasil uji Struktur Mikro (Microstruktur)}

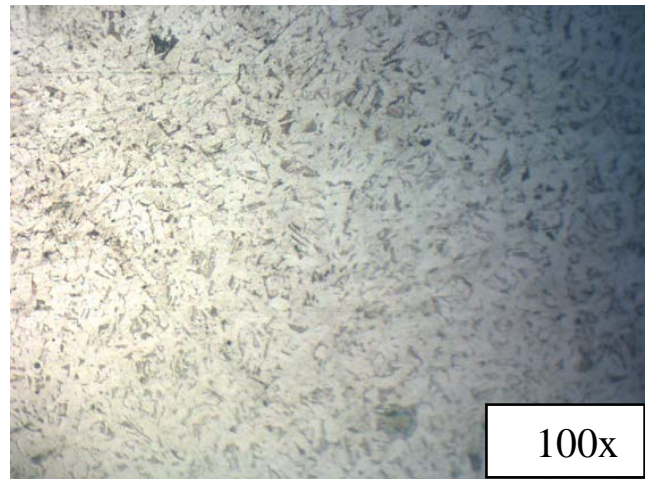

SMAW

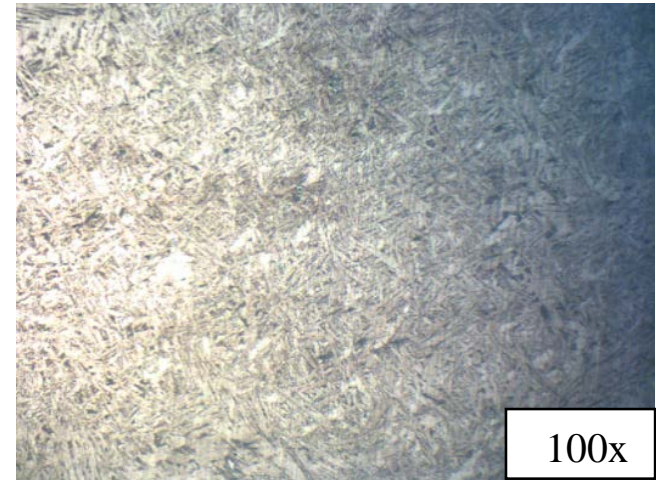

GTAW

Struktur mikro pada lasan SMAW dan GTAW berbeda dikarenakan oleh elektroda E-6013 maupun filler TGS50 mempunyai komposisi kimia yang berbeda.

\section{Hasil Uji Tarik (Tensile Test)}




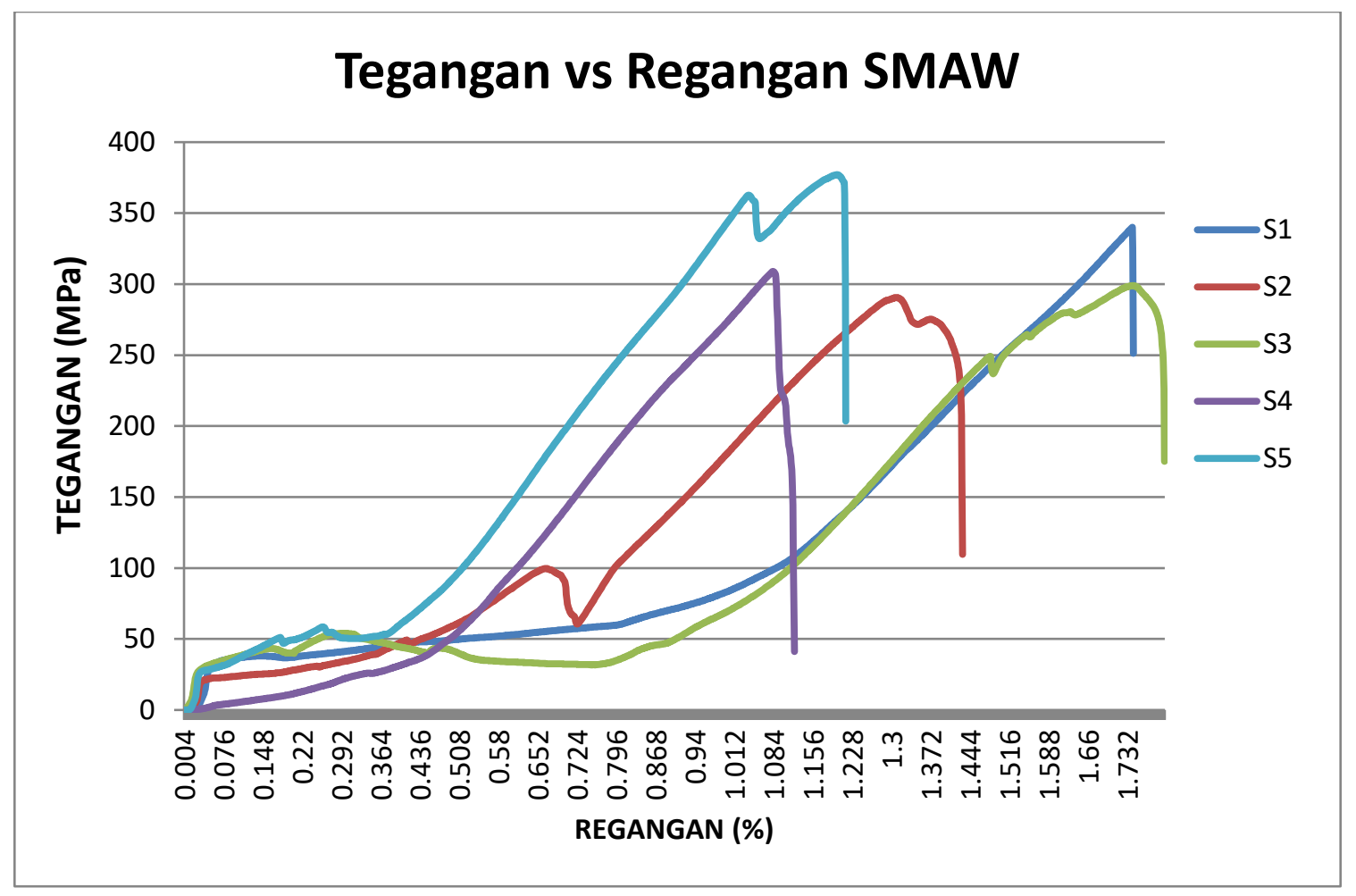

\section{Grafik 1 Tegangan vs Regangan pengelasan SMAW}

Pada pengujian ke-5 spesimen uji tarik las SMAW dengan elektroda E-6013 terhadap 100 Ampere didapatkan hasil yang beragam, dengan regangan tertinggi yaitu 1,7 \% dan tegangan tertinggi yaitu 377,12 MPa.

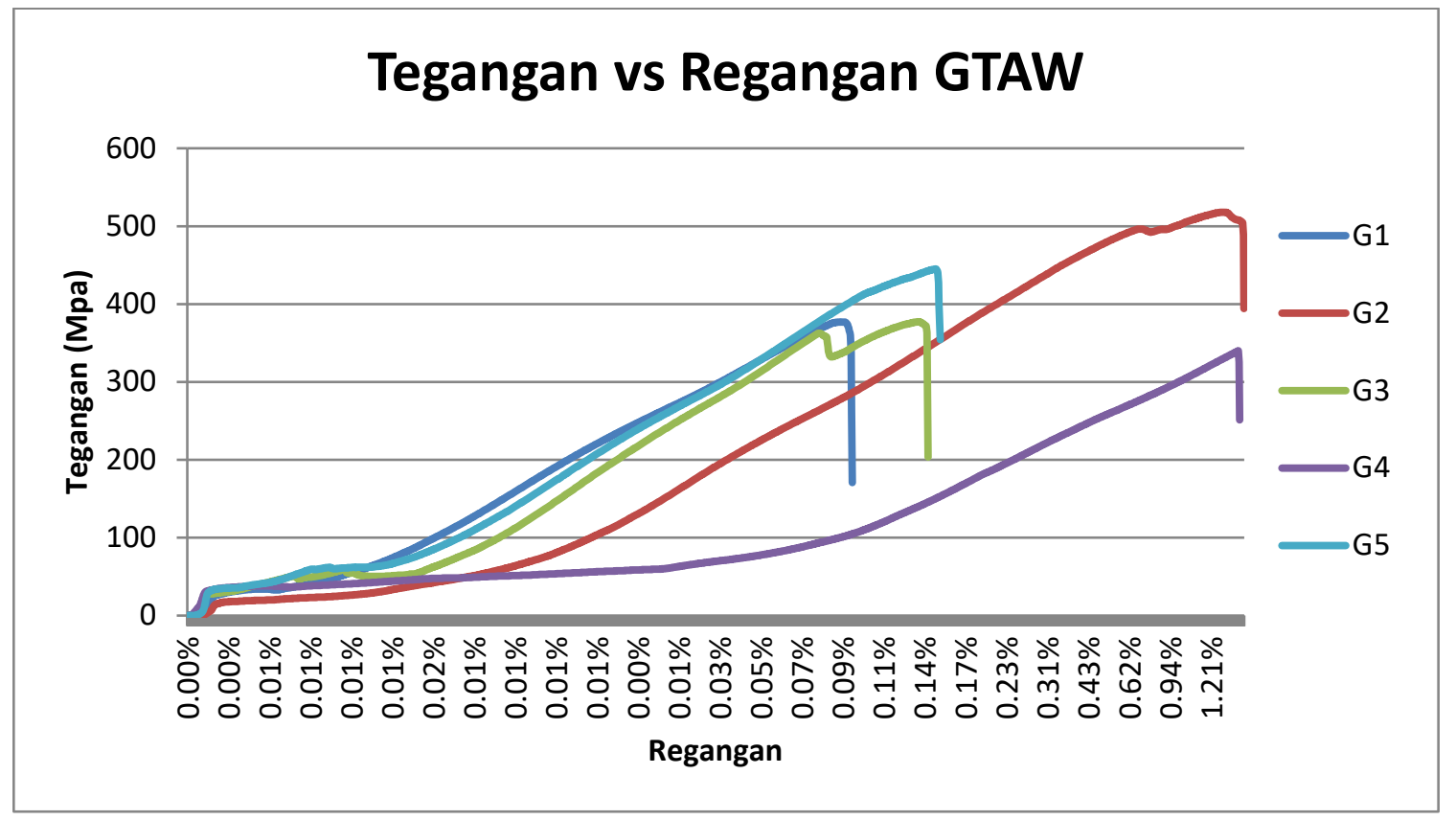

\section{Grafik 2 Tegangan vs Regangan pengelasan GTAW}

Pada pengujian ke-5 spesimen uji tarik las GTAW dengan filler TG S-50 terhadap 100 Ampere didapatkan hasil yang beragam, dengan regangan tertinggi yaitu 1,2 \% dan tegangan tertinggi yaitu 517,84 MPa. 


\section{KESIMPULAN}

1. Nilai uji kekerasan Brinell terbesar pada titik uji HAZ terdapat pada las GTAW dengan nilai 221,89 BHN, dan pada titik uji las (Weld Metal) terdapat pada las GTAW dengan nilai 176,68 BHN. Sedangkan nilai kekerasan terkecil pada titik uji HAZ terdapat pada las SMAW dengan nilai 187,26 BHN, dan pada titik las (Weld Metal) terdapat pada las SMAW dengan nilai 156,41 BHN.

2. Nilai rata-rata tegangan tarik dengan las GTAW menggunakan filler TG S-50 lebih tinggi dari pada las SMAW yang menggunakan elektroda E-6013.

3. Bentuk struktur mikro pada baja AISI 1045 sebelum pengelasan adalah struktur mikro Feritte, pada pengelasan GTAW dititik las (filler) dan SMAW di titik las (elektroda) adalah cementite, dan pada daerah HAZ (Heat Affective Zone) di SMAW maupun GTAW memiliki struktur mikro yang sama dengan sebelum dilas yakni feritte, namun dengan ukuran yang berbeda. Struktur mikro cementite pada daerah HAZ sudah mengalami perubahan (mengembang), inilah yang menyebabkan perubahan sifat mekanik material baja setelah pengelasan.

\section{DAFTAR PUSTAKA}

[1] Alip, M. 1989. Teori dan Praktik Las. Jakarta: Departemen Pendidikan dan Kebudayaan. Anonim. Peralatan Kamera Gamma Sentinel 880.

[2] Bintoro, G.A. 2000. Dasar-Dasar Pekerjaan Las. Yogyakarta: Kanisius.

[3] https://id.wikipedia.org/wiki/Las

[4] https://id.wikipedia.org/wiki/Baja

[5] Degarmo, E. Paul, Material and Processes in Manufacturing, McMillan Publishing Co. Inc., New York, 1969

[6] Groover, Mikell P. 1996. Fundamental Of Modern Manufacturing,Material, Proses And System. Penerbit Prentice-Hall Inc. USA.

[7] Hendi Saputra, 2014. Analisis pengaruh media pendingin terhadap kekuatan tarik baja st37 pasca pengelasan menggunakan las listrik. Jurnal Ilmiah, Universitas Lambung Mangkurat. Kalimantan Selatan.

[8] Jatmiko, S. \& Jokosisworo, S. Analisa Kekuatan Puntir Dan Kekuatan Lentur Putar Poros Baja JIS S45C Sebagai Aplikasi Perancangan Bahan Poros Baling-Baling Kapal. Semarang: Universitas Diponegoro.

[9] Kurnia, A. 2016. Analisa Dari Hasil Pengelasan SMAW Dengan Menggunakan Elektroda LB 52/E7016 Pada Plat Baja ST 60. Medan: Sekolah Tinggi Teknik Harapan.

[10] Novariandaru, A. 2014. Analisa Uji Visual dan Radiografi Pada Inspeksi Pengelasan Plat Baja Migas Cepu. Yogyakarta: Universitas Gadjah Mada.

[11] Surdia, T. \& Saito, S. 1999. Pengetahuan Bahan Teknik. Jakarta: Pradnya Paramita Cetakan ke IV.

[12] W, Harsono. T, Okumura, 2000. Teknologi Pengelasan Logam. Pradnya Pramita, Jakarta Cetakan ke VIII.

[13] Wiryosumatro, H. \& Okumura, T. Teknologi Pengelasan Logam. Jakarta: Pradnya Paramita Cetakan ke IX.

[14] Wiryosumarto, H. \& Okumura, T. 2000. Teknologi Pengelasan Logam. Jakarta: Pradnya Paramita Cetakan ke X.

[15] Widharto, S. 2004. Inspeksi Teknik. Jakarta: Pradnya Paramita.

[16] Zulkhamdi, A. H. 2009. Laporan Resmi Radiografi Test. Surabaya: Institut Teknologi Sepuluh Nopember

[17] https://www.azom.com/article.aspx?ArticleID=6130

[18] https://id.wikipedia.org/wiki/Baja_karbon

[19] https://www.academia.edu/10304254/karekteristik_mekanik_proses_baja_AISI

[20] Metallography, Structures, and Phase Diagrams, Vol 8, Metals Handbook, $8^{\text {th }}$ ed., American Society for Metals, 1973. 